\title{
Low back pain and fevers
}

\section{Ryan Sieve $^{1} \cdot$ Robert Wissman ${ }^{1}$}

Published online: 19 December 2015

(C) ISS 2015

A 33-year-old female presents with low back pain and fevers refractory to intravenous antibiotic treatment (Figs. 1, 2, 3 and 4).

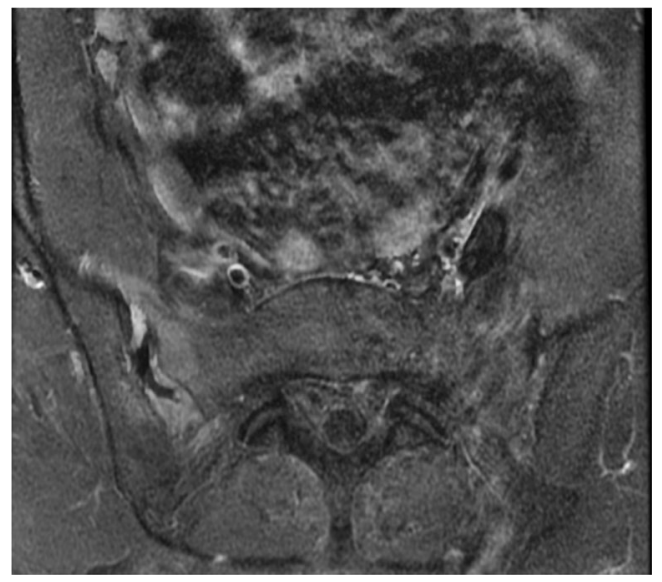

Fig. 1 Axial T1-weighted fat-saturated MR image of the pelvis following the administration of IV gadolinium.

The diagnosis can be found at doi: 10.1007/s00256-015-2311-5

Ryan Sieve

rcsieve@gmail.com

Robert Wissman

Robert.Wissman@uchealth.com

1 University of Cincinnati Medical Center, Cincinnati, OH, USA

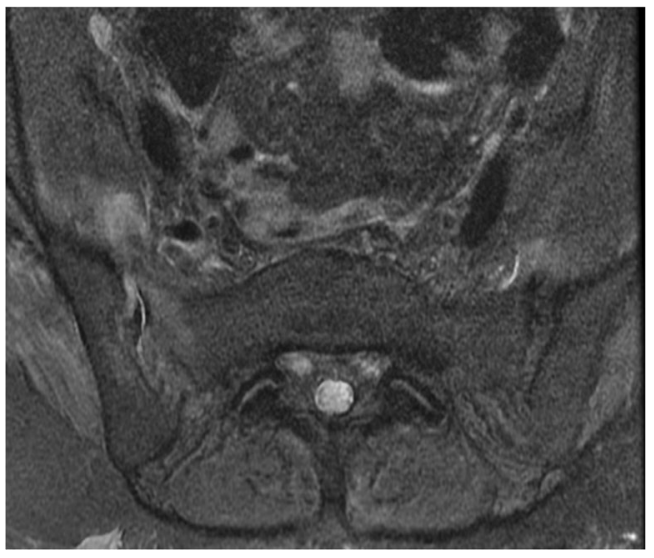

Fig. 2 Axial T2-weighted fast-spin echo fat-saturated MR image of the pelvis.

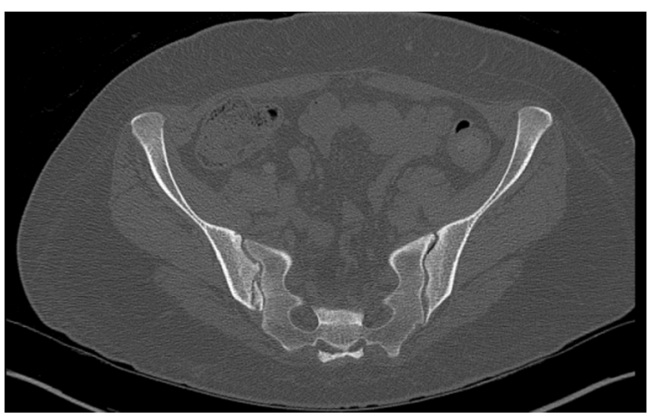

Fig. 3 Axial non-enhanced CT image of the pelvis. 


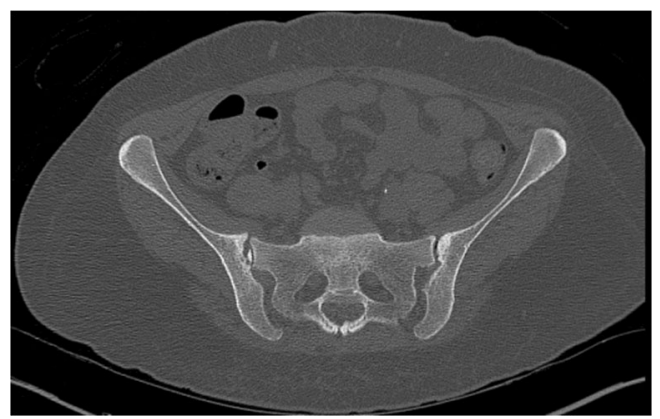

Fig. 4 Axial non-enhanced CT image of the pelvis. 